\title{
An integrated approach for soil classification: The Kingdom of Bahrain study case
}

\author{
Khalil Al-Joburi ${ }^{1 *}$ \\ ${ }^{1}$ University of Bahrain, Department of Civil Engineering, Isa Town, Bahrain
}

\begin{abstract}
Soil classification is a complicated and difficult process; the level of complexity depends on the extent of the information needed. The objective of this paper is to produce a digital soil map for the Kingdom of Bahrain. The Kingdom does not have such a map at the present time. Borehole data of more than 300 sites is collected form the Ministry of Work. Old maps are obtained from the Surveying Land Registration Bureau (SLRB). Multispectral LandSat images from the years 1973 to 1976 are downloaded from online sources. All paper format maps are scanned, geo-referenced and converted to GIS format. LandSat images are classified using supervised image classification; pixel value refers to a specific soil type. Borehole data is treated as a point feature and soil related information is entered as attribute data. A hybrid model that performs classification based on weighted average mean for the raster and vector data is developed. The model consists of calibration and execution module. The model is tested and a digital soil map for the Kingdom of Bahrain is produced. The map encompasses the historical Awal land and the newly reclaimed areas. Analysis revealed that there are solid waste dumping activities in the sea and lowland areas.
\end{abstract}

\section{Introduction}

Soil information is critical for Civil Engineering and construction activities, agricultural, land resource management, policy making, environmental monitoring, and all aspects of infrastructure development and planning. More than ninety percent of the world's food production is dependent on soil [1]. Soil and terrain information is needed for policymaking, land resource management, and for monitoring the environmental impact of development [2]. In fact, soil information constitutes a precious resource inventory associated with life on earth. Knowledge of soil types and spatial distribution is a prerequisite for any rational land use planning for agriculture, irrigation, drainage, etc. Soil information records provide an insight into the potentials, and limitations, of soil for effective and sustainable utilization. Soil information provides a truthful and scientific account of a soil's physical properties and the extent of distribution so that predictions can be made about their characters and possible effective utilization. It also provides adequate information about characteristics of soils (e.g., texture, depth, particle-size characteristics,

\footnotetext{
${ }^{*}$ Corresponding author: kaljuboori@uob.edu.bh
} 
liquid limit, plasticity index, structure, stoniness, drainage, acidity, and salinity) which can be utilized for planning and development. Lack of comprehensive information about global, national or local land resources increases the risk of uninformed policy decisions, continued degradation of land and water resources, excessive carbon emissions to the atmosphere, and that the Millennium Development Goals will not be achieved [3]. Global and regional models that address climate change, land degradation, and hydrological processes need soil input parameters with complete area coverage, but currently there are only few spatially exclusive datasets available [4,5]. Recently professionals and researchers are using soil information in much more sophisticated ways.

The objective of this paper is to produce a digital soil map for the Kingdom of Bahrain based on a hybrid practical procedural model that integrates traditional and advanced methods. The new DSM will include the unclassified soil and the newly reclaimed areas.

\section{Soil mapping methods}

The goal of soil mapping is to classify soils into groups with similar properties and behaviour. The process depends for the most part on the intended applications. For Civil Engineering applications, bearing capacity is the most critical. For agriculture scientists, water content and organic properties are vital. Literature search shows that there are many classification methods available globally and they are used daily for engineering and scientific applications. However, they can be divided into two categories:

- Traditional methods;

- Advance methods.

A brief description of each follows.

\subsection{Traditional methods}

These methods attempt to classify soils based primarily on soil grain size, texture, degree of plasticity (for engineering purposes), soil weathering, chemistry, profile thickness, etc. for Pedological classifications. The process involves laboratories and field tests, the most common and widely used methods are Unified Soil Classification System (USCS), The American Association of State Highway and Transportation Officials (AASHTO) and Agricultural Soil Classification System (ASCS).

\subsection{Advance methods}

More information about soil properties in a digital format is increasingly needed for agricultural, engineering, and environmental applications. The concept of digital soil mapping is adopted. The term is defined as "the creation and population of spatial soil information by the use of field and laboratory observational methods coupled with spatial and non-spatial soil inference systems' [6-8]. The new advanced methods utilize remote sensing, Geographic Information Systems (GIS) and Digital Elevation Model (DEM) and others to provide soil information in a Digital Soil Map (DSM) format that can be easily integrated and spatially analyzed. These methods attempt to classify soils based primarily on spectral data reflected or emitted energy in visible, thermal, and microwave zones. A number of factors generally govern the spectral response patterns of soil. The properties of soils that govern spectral reflectance are color, texture, structure, mineralogy, organic matter, free carbonates, salinity, moisture, and the oxides-hydroxides of iron and manganese. Chemical compositions of the soil influence spectral signature of soils through the absorption processes in near infrared (NIR) and middle infrared (MIR) domains. The 
process can be done using satellite imaging, aerial photography, and field spectroscopy and it is mostly performed based on local scale.

Soil properties are derived based on physical and empirical methods that have been measured using remote sensing. These include mineralogy, texture, soil iron, soil moisture, soil organic carbon, soil salinity, and carbonate content [2]. In complex landscapes, combinations of spectral and Digital Elevation Models (DEM) can significantly improve soil mapping. Typically, the surface is parameterized by attributes such as elevation, slope, aspect, plan and profile curvature, and flow accumulation [9]. Remote sensing presents potential for extending existing soil information in the two major ways:

- Remote sensing method reduces the need for costly filed work to map inaccessible areas.

- Remotely sensed data can be spatially analyzed to derive soil characteristics.

Moreover, remotely sensed imagery can be used as a data source supporting digital soil mapping $[10,11]$. Although remote sensing and soil spectroscopy have been recognized as a potentially effective and cost-efficient technology, they are not yet routinely used in soil surveys. Our knowledge of how to apply advances in remote sensing to soil and terrain mapping is still incomplete [10]. There are many methods of deriving soil properties from remotely sensed images; the most common methods will be briefly reviewed. A list of other methods can be found in $[2,12]$.

\subsection{Automated classification}

In these methods, multispectral passive imagery and active Radar images are often used. Pixels of similar spectral signatures are grouped together. Their spectral properties indicate that they are very likely to present one practical land cover. The process can be done fully automated (unsupervised classification), or signature data for particular features spatially distributed is added as an input to enhance the classification process (supervised classification). Research shows that several important soil characteristics can be derive from satellite imagery, such as mineralogy, iron content, soil salinity, soil moisture, and vegetation indices [2]. Many commercial satellite platforms in visible, thermal and microwave ranges are available and are used for soil classification as shown in Table 1. Many researchers, to meet certain classification criteria based on field collection and production of the substance signature or spectral properties, continuously enhance the methods, example, fuzzy classification [13], object-based classification [14], expert driven multi-level approach, LIDR DEM and a combination of DEM classification and spectral data [15].

Table 1. Current most common used satellites for soil classification.

\begin{tabular}{|c|c|c|c|c|c|}
\hline Sensors & Category & Bands & Resolution $(\mathrm{m})$ & $\begin{array}{c}\text { Spectral range } \\
(\mu \mathrm{m} / \mathrm{cm})\end{array}$ & country \\
\hline LandSat & Passive & 8 & $15-60$ & $0.45-12.5$ & USA \\
\hline MODIS & Passive & 36 & $250-1000$ & $0.4-14.40$ & USA \\
\hline MERIS & Passive & 15 & 300 & $0.39-1.040$ & Europe \\
\hline ASTER & Passive & 15 & $15-90$ & $0.52-11.65$ & Europe \\
\hline Hyperion & Passive & 242 & 30 & $0.40-2.500$ & USA \\
\hline LISS II & Passive & 4 & 36 & $0.45-0.86$ & India \\
\hline SRTM & Active & $\mathrm{C}-\mathrm{X}$ & 30 & $2.5-8(\mathrm{~cm})$ & USA \\
\hline RADARSAT2 & Active & $\mathrm{C}$ & $30-100$ & $4-8(\mathrm{~cm})$ & Canada \\
\hline
\end{tabular}




\subsection{Vegetation indices}

Vegetation index is one of the most effective methods to estimate the status of vegetation in a certain area. The method is based on using the red and infrared channels of the Advanced Very High Resolution Radiometer (AVHRR) 4-km global resolution. The Normalized Difference Vegetation Index (NDVI) is calculated as NDVI = (Near Infrared Red - Red) / (Near Infrared Red +Red) [16]. It has become the most used product derived from NOAA AVHRR data. The techniques are primarily used for predicting the status of vegetation. Research shows it can be successfully used for soil organic matter.

\subsection{Predictive soil mapping methods}

Predictive Soil Mapping (PAM) can be defined as the development of a numerical or statistical model of the relationship among environmental variables and soil properties, which is then applied to a geographic database to create a predictive map [12]. It is a computer-assisted production of digital maps of soil types and soil properties. The objectives are to: (1) produce an efficient collection of soil data; (2) produce and present data that better represents soil; (3) explicitly incorporate expert knowledge in the model; (4) provide insight and understanding into the soil forming processes.

The methods use raster data modeling to better represent the actual soil reality. A raster grid cell presented in form of $\mathrm{X}, \mathrm{Y}, \mathrm{Z}$, where $\mathrm{Z}$ represents any physical soil attributes, while $\mathrm{X}$ and $\mathrm{Y}$ represent spatial location. The cell size presents the spatial resolution, which can change to acuminate for any scale depending on data availability. The raster grid cell is continuous in nature and a more realistic presentation of soil than traditional methods. It allows for a scientific way of accuracy assessment. These methods utilize the new advances in remote sensing, GIS, DEM, and fuzzy logic to greatly improve the way that soil maps are produced.

\subsection{Global and national soils and terrain digital database (SOTER)}

SOTER is a land resource information system based on the concept that features the land in which terrain and soil occur - incorporate processes and systems of inter relationships between physical, biological and social processes overtime [17]. The central goal of the SOTER program is to set up a worldwide geospatial database for soils and terrain, including digital geo-referenced soil map units and their attribute information. GIS is used to hold the necessary data manipulation, analysis, mapping, management, and potentially monitoring changes of soil characteristics and terrain resources. The SOTER method enforces a strict set of rules for delineation and definition of soil and terrain units.

The methodology can be used at any scale ranging from global to local. The SOTER method was initially developed in Russia and Germany and was then steadily adapted worldwide. The method is similar in many aspects to the traditional physiographic soil mapping approach, but it focuses on both the soil and terrain properties and dynamic relationships. Moreover, it focuses on creating a universal geo-referenced geospatial database. Underlying the SOTER methodology is the identification of areas of land with a distinctive pattern of soil properties, parent materials, lithology, surface form, slope, parent material, and soil. Tracts of land distinguished in this manner are named SOTER units. Each unit has its own unique combination of soil and terrain characteristics. The Food and Agriculture Organization of the United Nations (FAO) adopted the method and joined the World Soil Information (ISRIC) to develop a soil and terrain global database at a scale of $1: 1,000,000$. Choosing the proper most effective method(s) depends on several factors, such 
as the prime objective of soil classification, the scale or spatial at which the soil information is needed, the soil characteristics that are under investigation, cost and data accessibility.

\section{The study area}

The Kingdom of Bahrain is an archipelago of around 33 islands; the largest is the main island of Bahrain, all are low-lying islands between latitudes $26.100^{\circ}$ and $25.22^{\circ}$ North and longitudes $51.070^{\circ}$ and $50.160^{\circ}$ East [18]. They lay in an arm of the Arabian Gulf, known as the Gulf of Salwa, which separates the Qatar peninsula and Saudi Arabia (Figure 1).

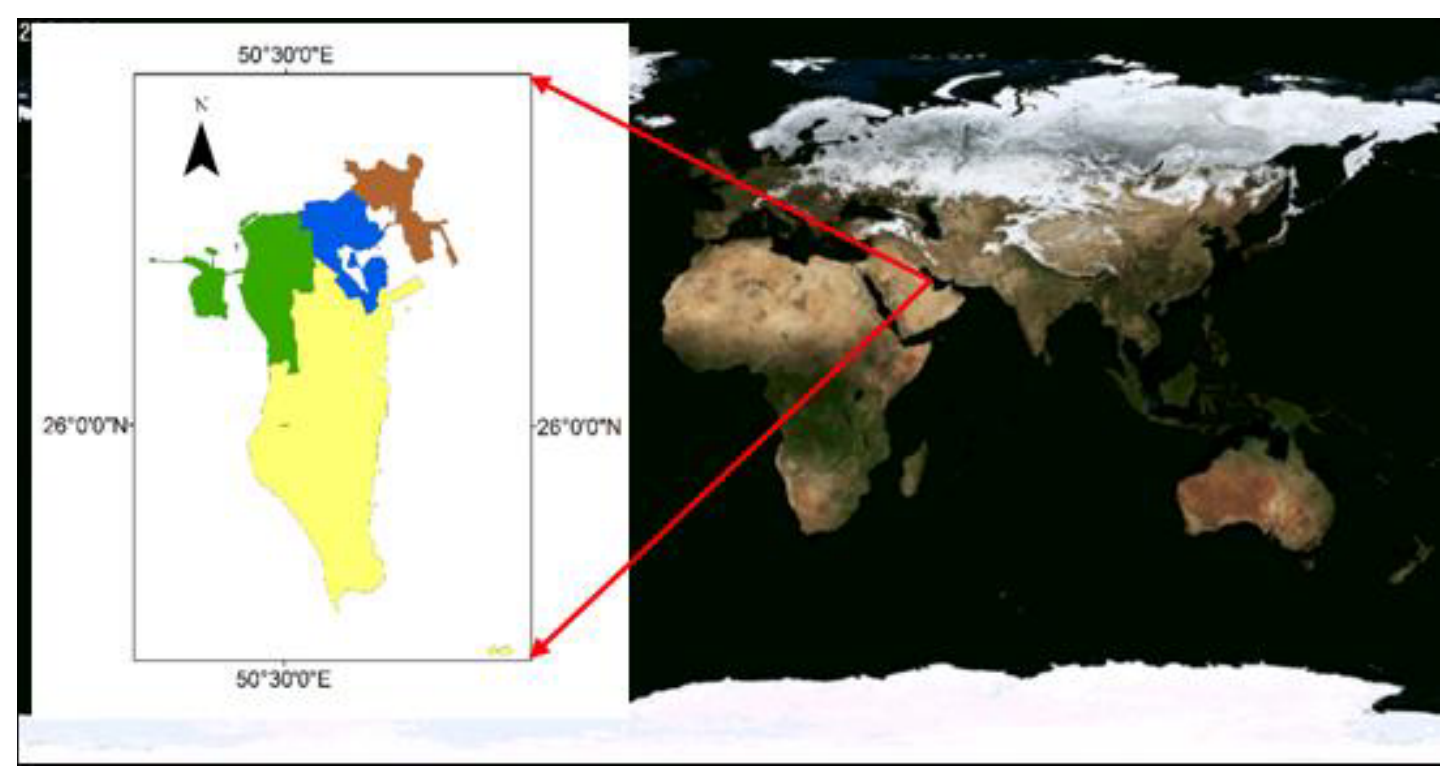

Fig. 1. Kingdom of Bahrain geographic location.

The Kingdom's total land area was about $620 \mathrm{~km}^{2}$ in 1965 [19]. Due to significant land reclamation activities since 1965, the estimated total area is $756 \mathrm{~km}^{2}$ [18]. This represents an increase of $22 \%$ in total square area, making the Kingdom the most dynamic country in the world in terms of land reclamation.

The surface soils of Bahrain were thoroughly investigated by the Bahrain Surface Material Resources Survey between December 1974 and April 1975. The team was made up of more than 20 scientists, geologists, surveyors, and engineers. They adapted the USCS approach to categorize soil map. Their work was presented in a book titled "GEOLOGY, GEOMORPHOLOGY AND PEDOLOGY OF BAHRAIN" published by Geo Abstracts Ltd. in 1980 [20]. Later it was published by E. M. BRIDGES and C. P. BURNHAM in 1980 in the Journal of Soil Science in an article titled "SOILS OF THE STATE OF BAHRAIN." The soil of Bahrain was placed in four groups: Cultivated Solonchaks, Natural Solonchaks, Regosols, and Rock dominated .The team produced a soil map for Bahrain (Figure 2). 


\section{Methodology}

To achieve the research objective a hybrid practical procedural model that integrated traditional and advanced methods and utilize paper format maps, classified satellite images, and borehole information. Since the Kingdom soil is partially classified, several challenges need to be addressed and examined thoroughly to decide the best and most effective approach. Among these issues are:

- Should the classification process follow the same schema that was used in 1975 or is new one needed? To ensure consistency and to be able to add the newly classified soil to that of 1975, the USCS classification schema is adapted.

- Should the classification process follow the same schema that was used in 1975 or is new one needed? To ensure consistency and to be able to add the newly classified soil to that of 1975, the USCS classification schema is adapted.

- To what extent can the boreholes data that is available for construction purposes can be used for soil classification? The borehole reports are mostly in PDF and some in excel format. Careful examination of a typical borehole report sample shows that it contains soil description, depth of water table and Standard Penetration Test (SPT-N). Accordingly, the borehole information is used for soil classification, as it provides an accurate field data that are similar to the ones used in 1975. Borehole data availability and accessibility are major problems that are encountered in this research. Large parts of the unclassified zones do not contain boreholes. Incorporating data within geospatial data base is a real challenge since researchers do not agree as yet on the best possible way of utilizing such data within GIS platform.

- How to classify the areas where there is no borehole data available? One option is to look into agriculture, geomorphology, geology, and drainage maps produced by the 1975 team. Vigilant inspection of this paper format shows that they are useful, but not enough to complete the classification process. The 1969 topographic map provides reasonable information about land use at that time, especially the agricultural areas. Another option is to utilize LandSat images. LandSat 1 and 2 of 1973 provide valuable information since they are within the same time frame. Supervised classification of LandSat 2 of 1973 is performed. Incorporating all these data in meaning and effective manner required special algorithm that is not currently available within ArcGIS environment.

- How to classify the newly reclaimed lands that is added to the the Kingdom and it estimated to be $136 \mathrm{~km}^{2}$. To classify the entire Kingdom soil a new approach has to be developed. The approach must incorporate the pervious work of 1975 and classify the remaining soil using the same schema. The outcome of the proposed approach must be a complete digital soil map that is to be used as a stand alone or along other spatial data.

\section{The proposed technique}

As such, a hybrid method that incorporates more than one technique and makes the most use of available sources would be a better option. Design such model and in a manner that can encompass all available forms of available input data is a challenge. All input data have to be converted into digital raster format and geo-referenced. Raster cells values represent soil type. Each input data is assigned different weight based on ground truth. Example borehole information is assigned the highest weight and drainage information is the least. Further more each output raster cell is determined individually based on its own spatial location. The model consists of calibration and execution phases. The calibration phase is designed to compute the appropriate weight. Execution phase determines the actual soil type based on weight average mean. Figure 3 illustrates the conceptual model. 


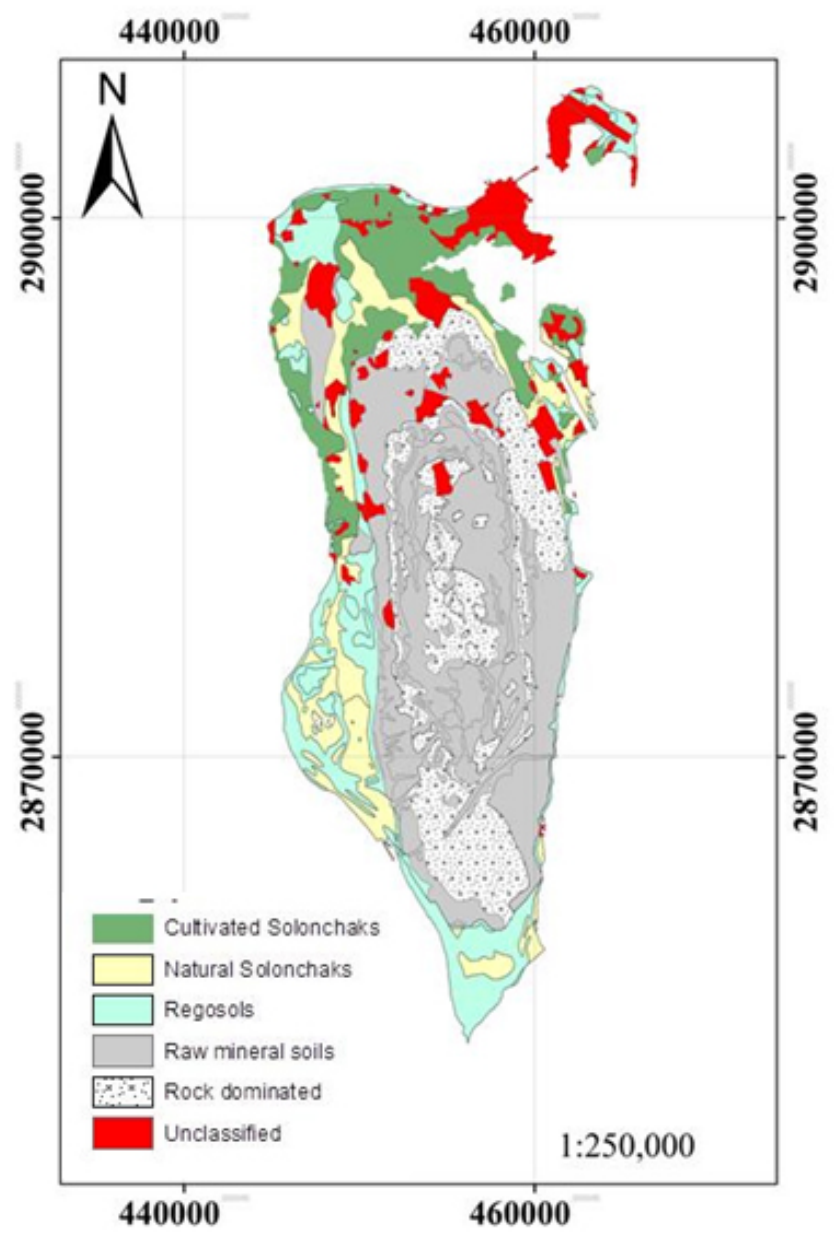

Fig. 2. Bahrain Soil Classification of 1975 , note urban areas are not classified.

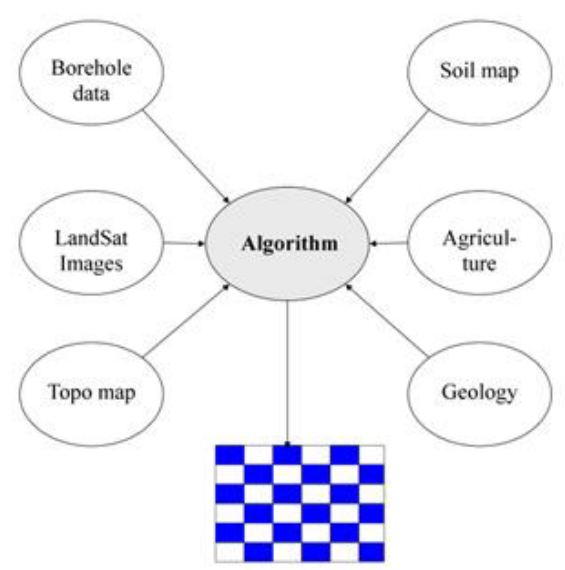

Computed cell values which represent soil category

Fig. 3. Algorithm conceptual model. 


\section{Results}

Following the classification process outlined above, a complete digital soil map for the Kingdom of Bahrain is produced (Figure 4). Accuracy of the obtained results is checked against ground truth for selected areas. Matching rate between the determined soil category and field data is ranged between $85 \%$ to $95 \%$. The zones where there was low match rate are the areas that have no borehole data. The soil boundaries were not clearly identified due to the lack of borehole data in some areas. Digital soil map for the Kingdom of Bahrain is produced. The map encompasses the historical Awal land and the newly reclaimed areas. The produced digital map has many advantages over the current paper format map. The most important is the ability to be utilized for spatial analysis along with other theme layers and non-spatial statistical data. It can be used in conjunction with other spatial and attribute information for many construction and infrastructure activities. Analysis revealed that there are solid waste dumping activities in the sea and lowland areas in Manama and Muharraq that contains domestic and building-construction municipal solid waste.

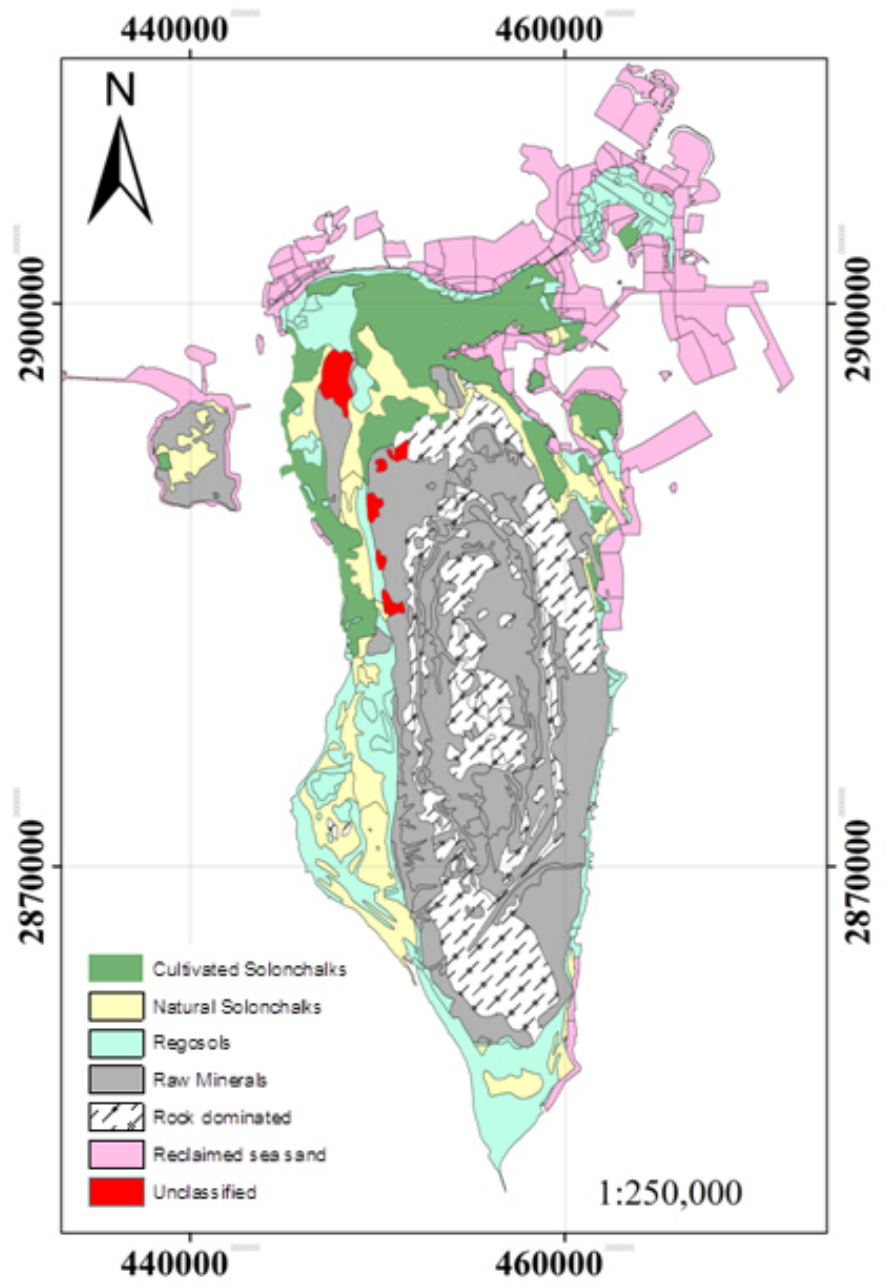

Fig. 4. Completed Bahrain digital soil map. 


\section{Conclusion}

Soil information records provide an insight into the potentials, and limitations, of soil for effective and sustainable utilization. Soil information provides a truthful and scientific account of a soil's physical properties and the extent of distribution so that predictions can be made about their characters and possible effective utilization. It also provides adequate information about characteristics of soils (e.g., texture, depth, particle-size characteristics, liquid limit, and plasticity index, structure, stoniness, drainage, acidity, salinity) which can be utilized for planning and development. Producing digital soil map that can be easily integrated with other data is difficult and challenges. The Kingdom of Bahrain does not have such map. This research produced the first digital GIS ready soil map. Soil map of the reclaimed lands is mostly sea sand and shell deposit with no trace of clay or silt.

\section{References}

1. Venkataratnam L. \& M.L. Manchanda. Remote sensing in soil resource management. ISPRS Workshop on Application of Remote Sensing and GIS for Sustainable Development. National Remote Sensing Agency, Hyderabad, Nov. 24-25 (1997).

2. Mulder V.L. et al The use of remote sensing in soil and terrain mapping - A review, Geoderma, (2011) . doi:10.1016/j.geoderma.2010.12.018.

3. Van Engelen V. e-SOTER, Annex 1 - Description of Work. EU 211578, ISRIC. Wageningen, The Netherlands report, (2008).

4. Anderson M.C. A thermal-based remote sensing technique for routine mapping of land-surface carbon, water and energy fluxes from field to regional scales. Remote Sens. Environ, 4227-4241, 112,12 (2008).

5. Bastiaanssen W.G.M. et al. SEBAL model with remotely sensed data to improve water-resources management under actual field conditions. J. Irrig. Drain. Eng. , 8593, 131,1 (2005).

6. Lagacherie P., McBratney A.B., Voltz M. Digital Soil Mapping: An Introductory Perspective. Elsevier, Amsterdam, (2006).

7. McBratney A.B., Santos M.L., Minasny B. On digital soil mapping. Geoderma, 3-52, 117,1-2 (2003).

8. Carré F., McBratney A.B., Mayr T., Montanarella L. Digital soil assessments: Beyond DSM. Geoderma, 69-79, 142,1-2 (2007).

9. Moore A.B., Morris K.P., Blackwell G.K., Jones A.R., Sims P.C. Using geomorphological rules to classify photogrammetrically-derived digital elevation models. Int. J. Remote Sens. , 2613- 2626, 24,13 (2003).

10. Ben-Dor E. et al Imaging spectrometry for soil applications. Adv. Agron. 97, 321-392 (2008).

11. Slaymaker O. The role of remote sensing in geomorphology and terrain analysis in the Canadian Cordillera. Int. J. Appl. Earth Obs. Geoinf. , 7, 3,1 (2001).

12. Sculla P., Franklina J., Chadwickb O., McArthura D. Predictive soil mapping: a review. Progress in Physical Geography, 171-197, 27,2 (2003).

13. MacMillan R.A., Jones R.K., McNabb D.H. Defining a hierarchy of spatial entities for environmental analysis and modeling using digital elevation models (DEMs). Comput. Environ. Urban Syst. 175-200, 28,3 (2004).

14. Irvin B.J., Ventura S.J., Slater B.K. Fuzzy and isodata classification of landform elements fromdigital terrain data in Pleasant Valley, Wisconsin. Geoderma, 137-154, 77,2-4 (1997).

15. Klingseisen B., Metternicht G., Paulus G. Geomorphometric landscape analysis using a semi-automated GIS-approach. Environ. Modell. Softw. , 109-121, 23,1(2008). 
16. Tucker J., Pinzon J., Brown M. An extended AVHRR 8-km NDVI dataset compatible with MODIS and SPOT vegetation NDVI data. International Journal of Remote Sensing 4485-4498, 26,20 (2005).

17. [17] Van Engelen W.P.V. Global and national soils and terrain digital databases (SOTER) procedures manual. International Soil Reference and Information Centre, Wageningen, The Notherland, report (2013).

18. Zainal K., Al-Madany I., Al-Sayed H. The cumulative impacts of reclamation and dredging on the marine ecology and land-use in the Kingdom of Bahrain, Marine Pollution Bulletin, 1452-1458, 64 (2012).

19. Noor Al-Nabi M. The History of Land use and Development in Bahrain. Manama, Kingdom of Bahrain, 16 (2012).

20. Doornkamp J. C, et al. GEOLOGY, GEOMORPHOLOGY AND PEDOLOGY OF BAHRAIN, 314-320 (Norwich, England 1980). 